\title{
The Liquid-Phase Hydrogenation of Citral to Citronellal at Hydrogen Pressure
}

\author{
U. Syunbayev, D. Kh. Churina, G. Y. Yergaziyeva, N. A. Assanov, and K. K. Kalihanov
}

\begin{abstract}
The aim of the work is to obtain citronellal that is the odoriferous substance and refers to the fragrant compounds used in perfumery and in the food industry as a flavoring. It is a raw material for producing aromatic substances - izopulegol, menthol, citronellol et al.

The hydrogenation of citral to citronellal was investigated over the catalysts on the base of VIII group metals using special high-pressure kinetic (KEHP) equipment allowing to keep the liquid phase hydrogenation process for any constant hydrogen pressure in a wide variation of the experimental conditions.

On the activity of the catalysts studied are located in the following sequence: NiR $>$ Pt $>$ Pd $>$ Rh $>$ Ni-black $>$ Ir $>$ Os $>$ Ru.

The effect of different key parameters of the process (nature of the solvent, reduction temperature of catalyst, hydrogen pressure, etc.) on the kinetics and selectivity of the hydrogenation of citral to citronellal over the supported nickel catalysts were studied.
\end{abstract}

Index Terms - Nickel-containing catalyst, citral, citronellal, hydrogen.

\section{INTRODUCTION}

Experts estimate that over a prolonged time for obtaining of complex organic compounds to relatively mild temperature conditions is using the method of liquid-phase hydrogenation in the presence of a catalyst batch wise. Increase in production of perfumery and cosmetic industry can't be achieved by simply increasing the number of machines, plants and factories. It is necessary to intensify the process and increase the removal of output per unit volume of the device. Progress in this area will significantly reduce the capital cost to implement the plan of perfume and cosmetics industry, will allow to emerge victorious in the competition, as well, is very important for the existence and prosperity of the industry or a single plant in the world economy [1]-[3].

Only for comprehensive works on the development and implementation of new and effective technological schemes, intensification of the main stages of production of odoriferous substances, in particular, the hydrogenation processes and

Manuscript received April 7, 2015; revised June 20, 2015. This work was supported in part by Ministry of Education and Science of the Republic of Kazakhstan.

U. Syunbayev and Yergaziyeva G. are with Institute of Combustion Problems MES RK Almaty, Kazakhstan (e-mail: Syunbaev51@mail.ru, ergazieva_g@mail.ru).

Churina D. and Assanov N. A. are with Center of Physical-chemica Methods of Investigations and Analysis of al-Farabi Kazakh National University, Almaty, Kazakhstan (email: dina.churina@gmail.com, Naukhan.Asanov@kaznu.kz).

K. Kalihanov is with Institute of Combustion Problems MES RK, Almaty, Kazakhstan (email: kunya-kz@mail.ru). plant to a continuous process for producing desired products will allow to successfully solve the task.

It should be noted that in the literature as well as in the production of practically no data for the selective hydrogenation of organic compounds with conjugated double bond on stationary catalysts in the liquid phase [4], [5].

Thus, a systematic study of the influence of different parameters on the selectivity of the hydrogenation of aromatic substances in batch mode and in the channel of interest in two respects.

On the one hand, these data provide new information that enhance understanding of the general laws of this process, supplementing and clarifying the existing theoretical views on this issue. On the other hand - allows optimum suspended and fixed catalysts and conditions for the batch and continuous process for selective hydrogenation of organic substances taken.

In this regard, the development of scientific bases and cooking techniques of new, cheaper, selective catalysts and cost-effective technologies for the synthesis of continuous commercial products offer great prospects for the production of perfume and food industries [6]-[9].

This article presents the results of a study of the liquid-phase hydrogenation of citral as a model substance in the presence of VIII Group metals (Pd, Ni, Pt, Os, Rh, Ru, Ir -black, NiR) in a wide variation of the experimental conditions. A feature of this work is to study the kinetics of the development of active catalysts for the selective hydrogenation of citral in batch mode.

\section{EXPERIMENTAL}

In carrying out this work were used all the main types of equipment used for the study of hydrogenation processes at pressurizing hydrogen pressures (Fig. 1). To solve the problems we used a special high-pressure kinetic (KEHP) equipment allowing to keep the liquid phase hydrogenation process for any constant hydrogen pressure of 0.1 to $9.8 \mathrm{MPa}$ and the reaction rate measured by the absorption of hydrogen per unit time. Major components of the apparatus (reactor surge vessel, piping) are made of stainless steel H18N1OT, fine adjustment of the valves and other parts of steel X 45 .

Reaction was carried out in a glass ampoule, which bears a weighed catalyst and hydrogenated substance solvent.

Supported catalysts $\mathrm{Ni} / \mathrm{Cr}_{2} \mathrm{O}_{3}, \mathrm{Ni} / \mathrm{Al}_{2} \mathrm{O}_{3}, \mathrm{Ni} / \mathrm{SiO}_{2}$ were laboratory prepared to work as follows. The catalyst must be crushed in a conventional porcelain mortar, and then add as a powder to a special recovery furnace. Reduction is carried out in a stream of hydrogen at a predetermined temperature for a certain time. After furnace cooling the reduced catalyst in 
hydrogen must be transferred to a special solvent ampoule. The thus prepared catalyst can also be applied in an autoclave to carry out a hydrogenation process.

Hydrogen from cylinders containing $0.3 \mathrm{mg} /$ liter of moisture, oxygen, not more than $0.003 \%$, obtained by electrolysis, used without further purification.

Chromatographic analysis of citral and citronellal and hydrogenation products was carried out on a chromatograph "Chromium 1000" with a flame ionization detector, carrier gas - helium.

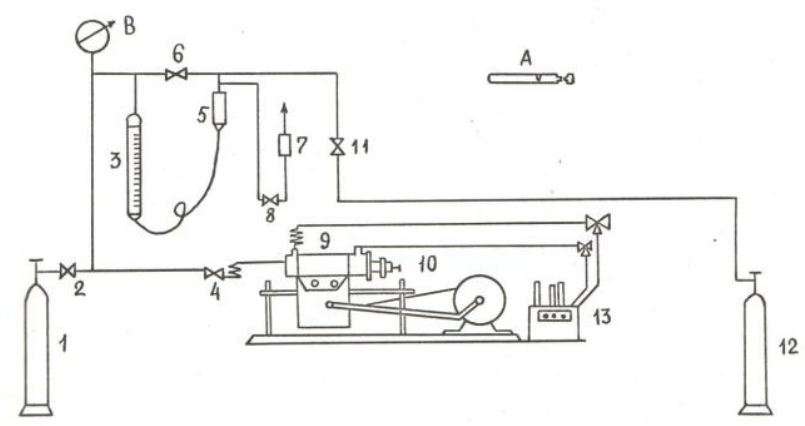

1 - a cylinder with $\mathrm{H}_{2}$ of 150 atm; 3 - burette; 5 - surge vessel; 7 - flame arrester; 9 - catalytic "duck"; 10 - Fleet rocking chair; 2,4,6,8,11 - fine adjustment valves; 12 - buffer with $\mathrm{H}_{2} ; 13$ - ultra-thermostat; B - manometer, A - substance vial.

Fig. 1. Technological scheme of installation KEHP.

The experiments were carried out in the following order. A hitch of the catalyst included in the vial with a specific volume of solution per hour is saturated with hydrogen at a predetermined pressure and temperature of the experiment, is then introduced citral weighed for hydrogenation.

Before saturation and hydrogenation the system was purged with hydrogen volume of 1.5-2.0 1, which corresponded to 7-10 times the volume of gas in the system. Impermeability of the system before the experiment was tested for 20-30 minutes at zero mark. The ampoule was placed in a catalytic "duck", mounted on a high-speed shaker with a stirring rate of 700 per minute sided swing at the amplitude of the oscillations of $10 \mathrm{~cm}$, which allows to realize the reaction in the out kinetic area.

Reliability is characterized by kinetic results reproducibility of experimental data and the accuracy of a single measurement, according to our experimental data and the calculation of the maximum possible error kinetic measurements in our experiments does not exceed 5-7\%. When carrying out the experiments, the emphasis was clean hydrogenated compound and solvent. After cleaning solvents and citral have physical-chemical constants corresponding reference.

\section{RESULTS AND DISCUSSION}

The following reaction is taken as a basis of process:<smiles>CC(C)=CCCC(C)C=O</smiles>
citral citronellal
The citronellal is the odoriferous substance and refers to the fragrant compounds used in perfumery and in the food industry as a flavoring. It is a raw material for producing aromatic substances - izopulegol, menthol, citronellol et al.

In the hydrogenation of citral to citronellal were studied VIII group metals ( $\mathrm{Pd}, \mathrm{Ni}, \mathrm{Pt}, \mathrm{Os}, \mathrm{Rh}, \mathrm{Ru}, \mathrm{Ir}$-black, NiR) under the condition of $2.0 \mathrm{MPa}$ and $303 \mathrm{~K}$, as a solvent was used $96 \%$ ethanol. The results are shown in Table I.

TABLE I: CATALYSATE COMPOSITION (AT THE TIME DESORBTION OF 1 MOL $\mathrm{H}_{2}$ ) IN THE HYDROGENATION OF CITRAL ON METALS OF GROUP VIII

\begin{tabular}{ccccc}
\hline \hline \multicolumn{5}{c}{ Yield of the products, \% } \\
& citral & citronellal & citronellol & $\mathrm{S}, \%$ \\
\hline $\mathrm{Pd}$ & 13.5 & 74.5 & 11.0 & 75.3 \\
$\mathrm{Pt}$ & 39.0 & 22.0 & 38.4 & 36.1 \\
$\mathrm{Rh}$ & 24.0 & 52.0 & 24.0 & 68.4 \\
$\mathrm{Ru}$ & 4.0 & 90.0 & 6.0 & 93.7 \\
$\mathrm{Ni}$ & 11.5 & 77.0 & 11.5 & 87.0 \\
$\mathrm{Ir}$ & 21.0 & 60.0 & 12.0 & 60.3 \\
$\mathrm{Os}$ & 46.0 & 16.0 & 16.0 & 29.6 \\
\hline \hline
\end{tabular}

Table I shows that on the selectivity for the hydrogenation of citral to citronellal investigated catalysts arranged in the following: $\mathrm{Ru}(93.7 \%)>\mathrm{Ni}(87.0 \%)>\mathrm{Pd}(75.3 \%)>\mathrm{Rh}$ $(68.4 \%)>\operatorname{Ir}(60.3 \%)>\operatorname{Pt}(36.1 \%)>$ Os $(29.2 \%)$.

On the activity of the catalysts studied are located in the following order: $\mathrm{NiR}>\mathrm{Pt}>\mathrm{Pd}>\mathrm{Rh}>\mathrm{Ni}$ - black $>\mathrm{Ir}>\mathrm{Os}>$ $\mathrm{Ru}$.

At the hydrogenation on $\mathrm{Pt}$ and Os in catalysate remains unreacted citral $(\approx 40 \%)$.

So, more selective catalysts for hydrogenation of citral to citronellal than the more complete is the hydrogenation process. In catalysate remains about $4 \%$ of citral.

These results indicate that for the hydrogenation of citral as selective catalysts may be used metals based on nickel, ruthenium and palladium.

Given the number of indicators of economy and availability of our further studies for the selective hydrogenation of citral to citronellal were used deposited nickel catalysts. The application of nickel on the carrier increases the catalyst lifetime, enhance its activity and in most cases, a change of its selective action.

Nickel catalyst supported on carrier: $\gamma-\mathrm{Al}_{2} \mathrm{O}_{3}, \mathrm{SiO}_{2}, \mathrm{Cr}_{2} \mathrm{O}_{3}$, $\mathrm{Al}_{2} \mathrm{O}_{3}-\mathrm{Cr}_{2} \mathrm{O}_{3}$ are widely used in industry. Therefore, we investigated the influence of the nature of the solvent, temperature reduction and other key parameters of the process on the catalytic properties of industrial supported nickel catalysts.

The first step was to study the effect on the nature of the solvent on the hydrogenation process of citral over $\mathrm{Ni}-\mathrm{Cr}_{2} \mathrm{O}_{3}$ catalyst under hydrogen pressure $(0.5-9.8 \mathrm{MPa})$ at temperatures (283-343 K). As the solvent, alcohols are selected: methanol, ethanol, propanol, butanol, pentanol, hexanol, isopropanol and water (Table II).

The hydrogenation reaction of citral using as solvent a $\mathrm{C}_{1}-\mathrm{C}_{6}$ alcohols proceeds by a similar mechanism. The highest amount of citronellal $-80 \%$ was found when using as solvent the methanol. Complication of chemical structure of alcohols (in a series of ethanol - hexanol) has no significant effect on the selectivity of the hydrogenation of citral to citronellal and 
selectivity of the process is in the range $78-81 \%$ (Table II).

TABLE II: INFLUENCE OF THE SOLVENT NATURE ON THE CATALYSATE COMPOSITION OF THE HYDROGENATION OF CITRAL

\begin{tabular}{ccccc}
\hline Solvent & \multicolumn{3}{c}{ Composition of catalysate } & $\mathrm{S}, \%$ \\
& citral & citronellal & citronellol & \\
\hline methanol & 10.0 & 80.0 & 10,0 & 89.0 \\
ethanol & 16.0 & 68.0 & 16.0 & 81.0 \\
propanol, & 18.0 & 66.0 & 16.0 & 80.5 \\
butanol & 17.0 & 67.0 & 16.0 & 80.7 \\
pentanol, & 18.0 & 64.0 & 18.0 & 78.0 \\
hexanol & 19.0 & 63.0 & 18.0 & 77.7 \\
isopropanol & 18.0 & 64.0 & 18.0 & 78.0 \\
water & 12.0 & 76.0 & 12.0 & 86.4 \\
\hline \hline
\end{tabular}

Increasing of hydrogen pressure from 1.0 MPa to 9.8 $\mathrm{MPa}$ increases the reaction rate about 20 times that practically no effect on the shape of the kinetic curves. Reaction order with respect to hydrogen is close to the first.

When using water as a solvent, the hydrogenation process of citral is at a decreasing rate. Amount of citronellal is $76 \%$. Selectivity of the hydrogenation of citral to citronellal is $86.4 \%$ (Table II).

Analysis of the data on studied solvents allowed to select as the optimum solvent ethanol.

The second step was studying of effect of reduction temperature for Ni-black, $\mathrm{Ni} / \mathrm{SiO}_{2}, \mathrm{Ni} / \mathrm{Al}_{2} \mathrm{O}_{3}, \mathrm{Ni} / \mathrm{Al}_{2} \mathrm{O}_{3}$ $\mathrm{Cr}_{2} \mathrm{O}_{3}$ and $\mathrm{Ni}-\mathrm{Cr}_{2} \mathrm{O}_{3}$ on the selectivity and rate of hydrogenation of citral. The results are shown in Fig. 2.

As can be seen over all the studied catalysts hydrogenation of citral in our chosen conditions is decreasing with time speed. Over the catalyst $\mathrm{Ni}-\mathrm{Cr}_{2} \mathrm{O}_{3}$ compared with others hydrogenation is most rapid from $40 \mathrm{ml} / \mathrm{min}$.

The results showed that the specific activity of the catalysts studied is located in the following order: $\mathrm{Ni}-\mathrm{Cr}_{2} \mathrm{O}_{3}>\mathrm{Ni}$ / $\mathrm{Al}_{2} \mathrm{O}_{3}>\mathrm{Ni} / \mathrm{SiO}_{2}>$ Ni-black.

From experimental results it was shown that selectivity of the catalysts is in the following order: Ni- black $(87.0 \%)>\mathrm{Ni}$ $\mathrm{Cr}_{2} \mathrm{O}_{3}(78.7 \%)>\mathrm{Ni} / \mathrm{SiO}_{2}(74.6 \%)>\mathrm{Ni} / \mathrm{Al}_{2} \mathrm{O}_{3}(73.4 \%)$.

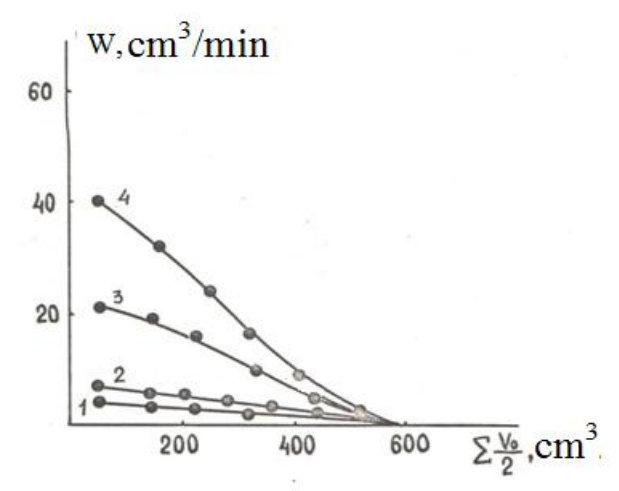

1 - Ni- black, 2 - Ni / $\mathrm{SiO}_{2}, 3$ - Ni / $\mathrm{Al}_{2} \mathrm{O}_{3}, 4$ - Ni / $\mathrm{Cr}_{2} \mathrm{O}_{3}$

Fig. 2. The hydrogenation of citral $\left(\mathrm{A}_{2 \mathrm{n} 2}=600 \mathrm{~cm}^{3}\right)$ at various media $\mathrm{Ni}(0.5$ g) in $96 \%$ ethanol at $2.0 \mathrm{MPa}$ and $303 \mathrm{~K}$.
The effect of different parameters of the process on the kinetics and selectivity of the hydrogenation of citral to citronellal in the presence of $\mathrm{Ni}-\mathrm{Cr}_{2} \mathrm{O}_{3}$ catalyst were studied.

The effect of hydrogen pressure on citral hydrogenation was studied over the catalyst $\mathrm{Ni}-\mathrm{Cr}_{2} \mathrm{O}_{3}(0.5 \mathrm{~g})$ in ethanol $(25$ $\mathrm{cm}^{3}$ ) at a temperature of $305 \mathrm{~K}$. The results are shown in Fig. 3.

In the hydrogenation of citral with increasing of hydrogen pressure in the system from 0.5 up to $9.8 \mathrm{MPa}$ kinetic curves changes significantly. So at low pressures $(0,5-3,9 \mathrm{MPa})$ process is characterized by a gradual decline in the rate of hydrogenation by time, and at the interval of pressure 5,9-9,8 $\mathrm{MPa}$ reaction rate is almost constant up to absorption of theoretically calculated amount of hydrogen $20-36 \%$.

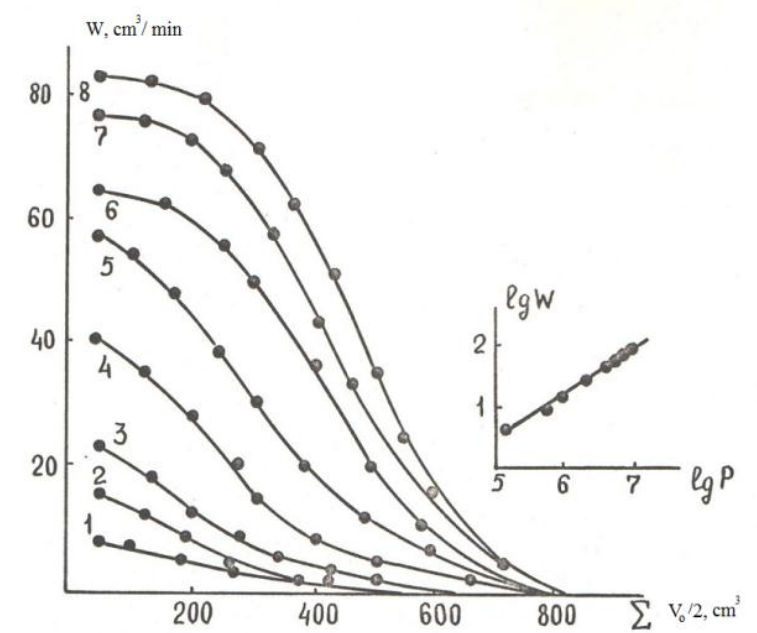

1 - 0.1 MPa; 2 - 0.5 MPa; 3 - 1.0 MPa; 4 - 2.0 MPa; 5 - 3.9 $\mathrm{MPa} ; 6$ - $5.9 \mathrm{MPa}$ 7 - 7.8 $\mathrm{MPa} ; 8$ - $9.8 \mathrm{MPa}$.

Fig. 3. Hydrogenation of citral at various hydrogen pressures.

The reaction rate with increasing of pressure from $0.5 \mathrm{MPa}$ to 9.8 increases almost proportionally. Reaction order with respect to hydrogen is close to the first.

With increasing of pressure from 0.1 to $9.8 \mathrm{MPa}$ selectivity of ranges $82-78 \%$, i.e. there is a certain tendency to decrease in selectivity with increasing hydrogen pressure in the range studied.

Investigations of the influence of the catalyst amount to the hydrogenation process of citral showed that between the catalyst amount and the rate of reaction the proportional dependence is observed (Table III).

Effect of amount of $\mathrm{Ni}-\mathrm{Cr}_{2} \mathrm{O}_{3}$ catalyst ranging from 0.25 to $1.0 \mathrm{~g}$ on citral hydrogenation was studied under a reaction pressure of $0.2 \mathrm{MPa}$ and a temperature of $303 \mathrm{~K}$. With increasing of amounts of catalyst from 0.25 to $1.0 \mathrm{~g}$ the selectivity decreases from 86.2 to $76.0 \%$ (Table III).

TABLE III: INFLUENCE OF THE CATALYST AMOUNT ON THE COMPOSITION CATALYSATE OF INCOMPLETE HYDROGENATION OF CITRAL

\begin{tabular}{ccccc}
$\begin{array}{l}\text { Quantity of } \\
\text { catalyst, g }\end{array}$ & \multicolumn{3}{c}{ Composition of catalysate } & $\mathrm{S}, \%$ \\
& citral & citronellal & citronellol & \\
& & & & \\
\hline 0.25 & 13.0 & 75.0 & 12.0 & 86.2 \\
0.5 & 17.0 & 66.0 & 17.0 & 78.7 \\
0.75 & 18.0 & 64.0 & 18.0 & 77.5 \\
1.0 & 19.0 & 62.0 & 19.0 & 76.0 \\
\hline \hline
\end{tabular}


These results indicate that unlike the hydrogen pressure change amount of the catalyst has a significant effect on the reaction rate and the selectivity of the process.

Next, we studied the effect of citral concentration on the process of hydrogenation at $303 \mathrm{~K}, 25 \mathrm{~cm}^{3}$ of ethanol, $0.5 \mathrm{~g}$ of $\mathrm{Ni}-\mathrm{Cr}_{2} \mathrm{O}_{3}$ catalyst.

According to information received increasing of concentrations of citral from 400 to $2400 \mathrm{~cm}^{3}$ (the hydrogen equivalent) at 2.0 and $7.8 \mathrm{MPa}$, the reaction rate decreases. Reducing the speed of the reaction with increasing of the concentration of citral in the solution, apparently due to increased effect of catalyst poisoning by reaction products at higher concentrations the compound to be hydrogenated. With increasing concentration of citral in the solution process selectivity increases from 77.7 to $87.6 \%$. Therefore, the higher the concentration of citral in the solution, the higher the selectivity of the process.

Raising the experiment temperature from 283 to $343 \mathrm{~K}$ has a significant impact on reaction rate and selectivity. The selectivity of the process with increasing of test temperature (283-343 K) falls from $84 \%$ to $72 \%$ (Table IV).

TABLE IV: EFFECT OF REACTION TEMPERATURE ON THE CATALYSATE COMPOSITION OF INCOMPLETE HYDROGENATION OF CITRAL

\begin{tabular}{ccccc}
\hline \hline $\begin{array}{l}\text { Temperature of } \\
\text { experiment, K }\end{array}$ & \multicolumn{3}{c}{ Composition of catalysate } & $\mathrm{S}, \%$ \\
& citral & citronellal & citronellol & \\
& & & & \\
283 & 14.0 & 72.0 & 14.0 & 83.7 \\
303 & 17.0 & 66.0 & 17.0 & 78.7 \\
323 & 20.0 & 60.0 & 20.0 & 73.5 \\
343 & 21.0 & 58.0 & 21.0 & 72.0 \\
\hline \hline
\end{tabular}

The influence of $\mathrm{Zn}, \mathrm{Cu}, \mathrm{Pb}, \mathrm{Mn}$ acetates to change the catalysate composition in the hydrogenation of citral over $\mathrm{Ni}-\mathrm{Cr}_{2} \mathrm{O}_{3}$ - catalyst at $303 \mathrm{~K}$ and $2.0 \mathrm{MPa}$ was investigated. The obtained results showed that increasing the concentration of zinc acetate of 10.0 to $30.0 \%$ by weight of the catalyst increases the selectivity from 84.0 to $87.6 \%$.

Note that increasing the zinc acetate concentration higher than $20 \%$ (by weight of the catalyst), the selectivity of the process is almost unchanged.

Changes in the concentration of copper acetate in the range of 5 to $30 \%$ rise the process selectivity from 84.0 to $86.0 \%$.

Maximum selectivity is achieved in the presence of copper acetate in an amount of $15.0 \%$ by weight of the catalyst. Further increasing the concentration of copper acetate in the solution does not affect the selectivity of the hydrogenation of citral to citronellal.

By adding lead acetate and manganese acetate about 5.0 to $30.0 \%$ selectivity increases from 86.4 to 89.0 and from 87.3 to $90.0 \%$, respectively. The maximum selectivity of the process in case of introduction into the reaction mixture of lead acetate and manganese acetate were achieved by adding these salts in an amount of $10.0 \%$ by weight of the catalyst.

\section{CONCLUSION}

Thus, based on the work done can be concluded that the effect of temperature and reduction time has an ambiguous influence on catalysts studied selectivity. In some cases (Ni / $\mathrm{SiO}_{2}, \mathrm{Ni} / \mathrm{Al}_{2} \mathrm{O}_{3}$ and $\mathrm{Ni} / \mathrm{Cr}_{2} \mathrm{O}_{3}$ ) process selectivity is almost independent from the variation of temperature and recovery time of the catalyst. In other cases (Ni-black) the variation of these parameters increases the selectivity of the process which may be caused as not full reduction of the catalyst and its agglomeration.

Study of the effect of process parameters on the activity of $\mathrm{Ni}-\mathrm{Cr}_{2} \mathrm{O}_{3}$ catalyst showed that, in contrast due to a pressure change in the amount of hydrogen the catalyst has a significant effect on the reaction rate and the selectivity of the hydrogenation of citral. Varying the basic parameters of the process and adding to the hydrogenated mixture cations $\mathrm{Zn}^{2+}$, $\mathrm{Cu}^{2}+\mathrm{Pb}^{2}, \mathrm{Mn}^{2+}$, can increase the selectivity of the hydrogenation of citral to citronellal.

\section{REFERENCES}

[1] R. Liu, Y. Yu, and K. Yoshida et al., "Physically and chemically mixed $\mathrm{TiO}_{2}$-supported $\mathrm{Pd}$ and Au catalysts: Unexpected synergistic effects on selective hydrogenation of citral in supercritical $\mathrm{CO}_{2}$," Journal of Catalysis, vol. 269, issue 1, pp. 191-200, 2001.

[2] J. C. Serrano-Ruiz, A. Sepúlveda-Escribano, F. Rodríguez-Reinoso, and D. Duprez, "Pt-Sn catalysts supported on highly-dispersed ceria on carbon: Application to citral hydrogenation," Journal of Molecular Catalysis A: Chemical, vol. 268, issue 1-2, pp. 227-234, 2007.

[3] H. Rojas, G. Díaz, J. José Martínez, C. Castañeda, A. Gómez-Cortés, and J. Arenas-Alatorre, "Hydrogenation of $\alpha, \beta$-unsaturated carbonyl compounds over $\mathrm{Au}$ and Ir supported on $\mathrm{SiO}_{2}$," Journal of Molecular Catalysis A: Chemica, vol. 363-364, pp. 122-128, 2012.

[4] T. Mitsudome and K. Kaneda, "Gold nanoparticle catalysts for selective hydrogenations," Green Chem, vol. 15, pp. 2636-2654, 2013.

[5] N. Perret, X. Wang, T. Onfroy, C. Calers, and M. A. Keane, "Selectivity in the gas-phase hydrogenation of 4-nitrobenzaldehyde over supported Au catalysts," Journal of Catalysis, vol. 309, pp. 333-342, 2014.

[6] L. A. Kovalev and L. V. Korchyn, "Economic incentive mechanisms organized gas market and its development prospects," Gas Industry, vol. 701, pp. 4-6, 2014.

[7] Oil and Gas Sector. [Online]. Available: http://www.kmgep.kz/eng/about_kazakhstan/oil_and_gas_sector

[8] W. Yu, M. Gregory, Mullen, and C. Buddie Mullins, "Interactions of hydrogen and carbon monoxide on $\mathrm{Pd}-\mathrm{Au}$ bimetallic surfaces," $J$. Phys. Chem, vol. 118, pp. 2129-2137, 2014.

[9] J. Aumo, J. Wärnå, T. Salmi, and D. Yu. Murzin, "Interaction of kinetics and internal diffusion in complex catalytic three-phase reactions: Activity and selectivity in citral hydrogenation," Chemical Engineering Science, vol. 61, issue 2, pp. 814-822, January 2006.

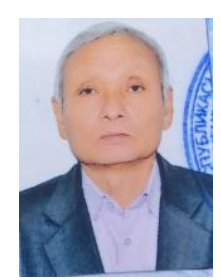

Syunbayev Ualihan was born in Alma-Ata on November 21, 1951. In 1983, he got candidate degree diploma at IOCE AS RK, Almaty, Kazakhstan. From 1977 to 1989 , he was a researcher of IOCE AS RK, Almaty, Kazakhstan. He is a senior researcher of Institute of Problem Combustions, Almaty, Kazakhstan since 2012. His Current and previous research interests are catalysis, petrochemistry, ecology. From 1980 to 1981, he has introduced his development in the Tulsnoi region pilot plant fragrance compounds. In 1988, he has introduced his development in the Moscow pilot plant fragrance compounds, Moscow. In 1989, he has introduced his development in the Kaluge of "Aromasynthesis" pilot plant fragrance compounds.

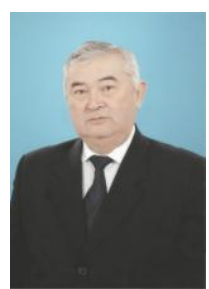

Assanov Naukhan Altaievich was born in Taldykorgan, Republic of Kazakstan on March 19, 1950. In 2006, he got his professor position, chemistry, al-Faraby Kaz NU, Almaty, Kazakhstan. In 2005, he got doctor degree diploma, pedagogue, al-Faraby Kaz NU, Almaty, Kazakhstan. In 1972, he got candidate degree diploma, al-Faraby Kaz NU, Almaty, Kazakhstan. He is the director of the Department on the academic 
questions, al-Faraby Kaz NU, Almaty, Kazakhstan since 2012. From 2008 to 2011, he was a rector Kazakh Economical University, Almaty, Kazakhstan. From 2001 to 2008, he was the head of Educational- methodical department al-Faraby Kaz NU, Almaty, Kazakhstan. From 1997 to 2001, he was the head of the department of certification NAS PK. From 1994 to 1997, he was the first vice-rector of Zhansugurov TNU, Taldykorgan, RK. From 1979 to 1994, Zhambyl Technical University, Zhambyl, RK. From 1972 to 1979, Institute of Chemical Sciences of the Kazakh SSR Academy of Sciences, Almaty, Kazakhstan. His current and previous research interests include pedagogue, catalysis, petrochemistry, ecology.

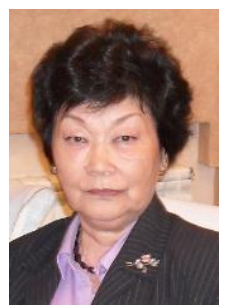

Churina Dina Khamidovna was born in Alma-Ata on November 17, 1943. In 1985, she got her leading her researcher diploma, Moscow, SU. In 1973, she got diploma of candidate of chemical science, catalysis, electrochemistry, Almaty, Kazakhstan. In 1965, she got her high education diploma Kaz SU, chemistry, catalysis, Almaty, Kazakhstan. She is a senior researcher CHMA al-Farabi Kaz NU, Almaty, Kazakhstan since 2011. From 1978 to 2010, she was a secretary of scientific affairs IOCE NAS RK, Almaty, Kazakhstan. From 1965 to 1978, she was a science researcher, engineer IOCE AS RK, Almaty, Kazakhstan. Her current and previous research interests are catalysis, electrochemistry, ecology.

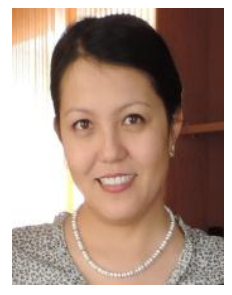

Yergaziyeva Gaukhar Yergaziyevna was born in Alma-Ata on September 27, 1979. In 2011, she got her diploma of candidate of chemical science, catalysis, Almaty, Kazakhstan. In 2002, she got the diploma of master KazNU al-Farabi, Almaty, Kazakhstan. In 2000, she got the diploma of bachelor KazNU al-Farabi, Almaty, Kazakhstan. In 2013, she was a leading science researcher of Institute of Combustion Problems. From 2003 to 2011, she was a senior science researcher, junior science researcher, and an engineer of IOCE NAS RK. Her current and previous research interests are catalysis, petrochemistry, ecology.

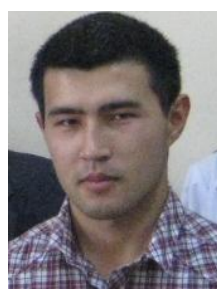

Kalihanov Kuanysh Kambarkhanuli was born in Semipalatinsk, Republic of Kazakstan on August 6 1993. In 2014, he got his diploma of bachelor KazNU al-Farabi, Almaty, Kazakhstan. He is an engineer of Institute of Combustion Problems MES RK, Almaty, Kazakhstan since 2012. And he is studying for master KazNU al-Farabi, Almaty, Kazakhstan since 2014. Hi current and previous research interests are catalysis, petrochemistry, ecology. 